\title{
Airport plans threaten dolphin sanctuary
}

Hong Kong. The Hong Kong government has bowed to pressure from local green groups and announced it is to set up a 1,000hectare marine sanctuary for the rare Chinese white dolphin (Sousa chinensis).

But campaigners are opposed to the government-funded HK\$18-million (US\$2.34 million) project, to be managed by the Agriculture and Fisheries Department (AFD). They argue that the future of the dolphins may be compromised by the siting within the sanctuary site of a temporary aviation fuel storage depot.

The Provisional Airports Authority (PAA), the government body set up in 1990 to plan, design and construct Hong Kong's new airport at Chek Lap Kok, was given approval in early April to begin construction of the Aviation Fuel Receiving Facility (AFRF) at Sha Chau, one of two islands to be included in the sanctuary. Fuel from the depot will be transferred to the airport platform by an under-sea pipeline.

Michael Lee, deputy director of the AFD, says that demarcation of the area will begin next year. But protesters say it should have been sited further away from an area used by the dolphins.

Joanna Ruxton, senior conservation officer for World Wide Fund for Nature Hong Kong, is convinced that a combination of human activity, the blasting during the construction of the fuel-receiving facility and the volume of shipping traffic to and from the site will be detrimental to the dolphins in an area that is their last stronghold. Their favoured habitat of shallow coastal waters is gradually disapearing as a result of development and dredging.
Other critics of the PAA include Lindsay Porter and Chris Parsons, two PhD researchers who are part of a HK\$2-million government-funded dolphin research project at the Hong Kong University Swire Institute of Marine Science.

But Richard Morse, environmental manager at PAA, argues that the authority has

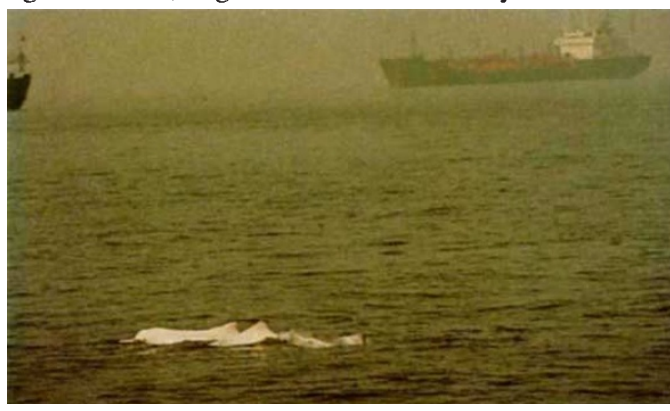

No hiding place: shipping already endangers habitat.

made a "good faith effort" to choose the best site for the fuel depot out of 10 possibilities. Under the "exhaustive process" for selection, undertaken in consultation with 16 other government departments, Sha Chau emerged as the "only viable option" after all environmental considerations were taken into account.

The Chinese white dolphin or Indopacific humpback dolphin, is found in coastal and estuarine waters from the southern tip of Africa, around India, Malaysia, down to northern Australia and north into the South China Sea. The taxonomic status of the different populations is still being debated - mainly because of a lack of research data - but the population in Chinese waters is remarkable in that grey calves fade to a

\section{Plans unveiled for giant ray detector}

Washington. Construction work on what a group of physicists hope will eventually be the world's largest detector of cosmic rays could begin as early as 1997 - providing funding can be raised from US and foreign sources - according to one of the leaders of the design project.

James Cronin of the University of Chicago was speaking during a meeting last week at the Fermi National Accelerator Laboratory near Chicago (Fermilab). The meeting took place halfway through a sixmonth design study which members of the Pierre Auger Cosmic Ray Project hope will lead to the construction of two large detector arrays, one each in the northern and southern hemispheres.

The arrays would be used for studying the most energetic particles in the universe. The project, which originated in 1992, would involve two arrays, each using 3,000 garage-sized detectors spaced over an area of 5,000 square kilometres and located in a striking pinky white as adults.

PAA says that independent experts have confirmed that a fuel facility based in Shau Chau is not likely to harm the dolphins. Bern Wursig, director of the marine mammal research programme at the Institute of Marine Life Sciences at Texas A \& M University, was brought in by the authority to examine the potential effects of the fuel facility on the dolphin population.

While Wursig concluded in his report that "the AFRF at Sha Chau, by itself, is not likely to have negative effects on Sousa as a population", he did recommend several mitigating measures, including the setting up of "the largest possible" sanctuary for the dolphins and an overall Hong Kong dolphin management programme.

Observers are unhappy that Wursig's conclusions were based on just four days spent with the dolphins. The Hong Kong University researchers, on the other hand, have spent 18 months in the field. But Wursig argues that these mammals "habituate remarkably well" to noise and interference caused by humans.

As evidence of this, Wursig cites the reappearance of the pink dolphins around the Brothers, a group of islands that were virtually removed for the airport's construction. It is, however, difficult to establish whether the same numbers of dolphins returned as there are no original figures for comparison.

Despite the differences of opinion on whether a dolphin sanctuary can be sited near a fuel facility, Ruxton, Parsons and Wursig share common ground in considering pollution a threat to the dolphins. "Things going on noise-wise [for the dolphins] are not so horrible. But the things going on pollution-wise and habitat-degradation-wise are horrible," says Wursig.

All three researchers believe that pollution from untreated sewage, heavy metal toxins, toxic mud pits resulting from dredging operations, over-fishing, increased volume of shipping traffic and the rapid removal of the shallow coastal habitat preferred by the dolphins, all combine to constitute a major threat to the dolphins.

But the dolphin/fuel receiving facility issue may have become a victim of the island's delicate but often murky politics the dolphin sanctuary may have been agreed in exchange for the fuel facility.

Nevertheless, Wursig wants the dolphins to benefit as much as possible. "The Provisional Airports Authority gave the sanctuary so that they could have their interim reserve facility," he says. "But it's now time for the green groups to say, okay, let's work together on this to put together the best programme for the dolphins." Maggie Verrall 